\title{
The Barrier and Driver Factors of Building Information Modelling (BIM) Adoption in Indonesia: A Preliminary Survey
}

\author{
Faizal Restu Utomo ${ }^{1}$ and Mohammad Arif Rohman ${ }^{2}$
}

\begin{abstract}
Building information modeling (BIM) changes institutions, businesses, business models, education, workplaces and careers. For an asset owner the implementation of BIM should seen as a business change program that can potentially impact their 'value proposition'. BIM can enable strategic business outcomes. BIM is useful for geometric modelling of a building's performance and it can assist in the management of construction projects. The construction industry in the world has recognized the benefits of BIM, therefore many large projects in developed countries have used BIM. In Indonesia, lately BIM has received more attention from construction industry players, even the Indonesian government through the public works agency issued guidelines for BIM adoption in 2018 with reference to developed country references such as Singapore. Many benefits can be obtained from the implementation of BIM, but the level of BIM adoption in Indonesia is still low. Thus, it warrants a study such as the present to determine what are the actual barriers that hamper its implementation and what are the driving factors that could enhance its pace of implementation in the Indonesian construction industry. This paper is an initial stage of the research to determine the barriers and driving factors of building information modelling (BIM) adoption in Indonesia. Following the variable identification from the literature, a preliminary survey involving eleven experts were conducted to verify several variables that have been identified from the literature to be used for the questionnaire survey. According to the experts' opinion, it was found that 16 variables were considered relevant to measure the barriers of BIM adoption in Indonesia and 18 variables were considered relevant to measure the driving factors of BIM Adoption in Indonesia. The three most relevant barriers BIM adoption in Indonesia attributes were also determined according to the experts' opinion, that are (1) Lack of BIM expert; (2) Lack of understanding about BIM and its benefits; (3) Resistance to change. The three most relevant drivers BIM adoption in Indonesia attributes were also determined according to the experts' opinion, that are (1) Willingness/intention; (2) Technological factors; (3) Organizational culture.
\end{abstract}

Keywords - Building Information Modelling, Barrier, Driver, BIM Adoption, Indonesia.

${ }^{1}$ Faizal Restu Utomo is with Departement of Management Technology, Institut Teknologi Sepuluh Nopember, Surabaya, 60264, Indonesia. Email: faiz.alrestu@gmail.com.

${ }^{2}$ Mohammad Arif Rohman is with Departement of Civil Engineering, Institut Teknologi Sepuluh Nopember, Surabaya, 60111, Indonesia. Email: arif@ce.its.ac.id

\section{INTRODUCTION}

Building information modeling (BIM) changes institutions, businesses, business models, education, workplaces and careers. BIM is the most significant technology changing how we design, build, use and manage the built environment. It is a popular topic in academic research although the theoretical groundwork was laid in the previous century. BIM is also dominant technological trend in the software industry[1]. For an asset owner the implementation of BIM should seen as a business change program that can potentially impact their 'value proposition'. it can enable strategic business outcomes[2]. BIM is useful for geometric modelling of a building's performance and it can assist in the management of construction projects[3]. Many benefits can be obtained from BIM implementation.

The construction industry in the world has recognized the benefits of BIM, therefore many large projects in deve loped countries have used BIM[3]. BIM is being heralded as something extraordinary innovation in the construction sector. Several countries have demonstrated a remarkable level of BIM adoption and noted evidence of the benefits of BIM[4]. BIM has been widely applied throughout the world, particularly in developed countries.

According to an international survey conducted by national building specification (NBS) United Kingdom (UK) in 2016 to several respondents in various countries, it was reported that the highest BIM adoption in Denmark was 78\%, then Canada 67\%, Britain 48\%, Japan 46\% and Czech Republic 25\%[5]. In Australia, BIM adoption made significant progress over the past decade[6]. BIM Adoption rates vary in various countries in the world. Countries in Southeast Asia have used BIM in the construction industry practice, especially in Singapore which has a high BIM adoption rate. In Indonesia, BIM has also been used, but compared to other countries, the development of BIM in Indonesia is still low[7]. [8] conducted a survey of several respondents from practitioners and academics in the field of architecture in several cities in Indonesia with the result that the level of awareness was quite high with $70 \%$ of respondents who knew BIM, but the level of implementation was still low with $38 \%$ using BIM. In Indonesia, currently BIM has received more attention from 
construction industry players, even the Indonesian government through the public works agency issued a guide to BIM adoption in 2018 with reference to developed country references such as Singapore[9]. Indonesia is the largest construction market in Southeast Asia and No.4 in Asia. The construction sector in Indonesia contributes 10\% to gross domestic product (GDP). The government has planned infrastructure development worth USD 450 billion until 2022. But construction efficiency and productivity in Indonesia is still weak. The level of expertise of construction human resource that has not been evenly distributed and lack of certification. The development of construction technology in Indonesia is also still low compared to developed countries. Indonesia has yet to have an international construction company[10]. All of this was revealed by the Indonesian government on 4 October 2017 through the International Conference of "digital construction day" event. At the event, the Head of the Research and Development Agency of the Ministry of Public Works and Housing (Pekerjaan Umum dan Perumahan Rakyat / PUPR) represented the Minister of PUPR, presenting the BIM implementation roadmap at the ministry of PUPR. The roadmap presented consists of several main stages, namely adoption, digitization, collaboration and finally integration which is expected to be achieved within a maximum of 5 years (2017-2022). Even after that, as a followup to the event, the BIM PUPR team was formed through the head of research and development agency tasked with overseeing the implementation of BIM within the ministry of PUPR.

From all the descriptions above, it can be concluded that the construction industry in Indonesia is under pressure to adopt BIM and adapt traditional work methods so that it can act as a driver for transformation and adjust the rise in construction technology levels throughout the world. At present, the level of low technology adoption in the construction industry in Indonesia and very little implementation of BIM in Indonesia, therefore it is very important to know the barrier and driver factors of BIM adoption in Indonesia. It is important to recognize before making a roadmap for BIM implementation by determining the barrier and driver factors that can increase the level of BIM adoption in the future. Given the very few

TABLE 1

BARRIER FACTORS OF BIM ADOPTION

\begin{tabular}{ccc}
\hline \hline No & Criteria & Source \\
\hline 1 & Lack of BIM education and training & {$[1],[16]-[18]$} \\
2 & Lack of understanding about BIM and its benefits & {$[15]-[17],[19]$} \\
3 & Lack of development of skills (BIM) & {$[6],[12],[16],[19]$} \\
4 & Contract or legal issues (ownership of data) & {$[13],[15],[16],[18],[19]$} \\
5 & Lack of BIM compliance for all types of development projects & {$[6],[12]$} \\
6 & Lack of effective collaborative work processes between project participants & {$[12],[13],[15]-[19]$} \\
7 & Expensive costs for BIM implementation & {$[6],[12],[13],[15],[16],[19]$} \\
8 & Doubt of return on investment (RoI) & {$[13],[16]$} \\
\hline \hline
\end{tabular}

publications about BIM in Indonesia[11] and to date there have been no studies of the barrier and driver factors of BIM adoption in indonesian construction industry. Therefore, research was conducted to fill this gap. This study aims to identify the barrier and driver factors of BIM adoption in Indonesia.

\section{LITERATURE REVIEW}

\section{A. Barrier Factors of BIM Adoption}

Apart from the extraordinary benefits, BIM also faces challenges as shown by the researchers. BIM is considered a new phenomenon that seeks to renovate practices carried out by the construction industry, making it more difficult to adopt and implement BIM. Different countries, different times, even different construction projects will provide different inhibiting factors for BIM adoption[12]. Many authors have divided the BIM barrier into different categories. [13] describe barriers by dividing into two groups, namely contract issues and personnel problems. However, [14] divided the barriers to BIM adoption into three different categories, namely technical issues, social context problems and problems related to work processes and practices. It's different from [12], which divides the classification of factors that inhibit BIM adoption into 5 groups, namely technology, cost, management, individuals, legal. [6] shows that the main inhibiting factor for BIM adoption is the lack of evidence that states that BIM is financially useful. Besides the limitation of resources and knowledge about BIM is a limiting factor for BIM adoption. [15] indicate that several factors inhibiting BIM adoption include lack of expertise in both the organization and the project team, lack of client demand, cultural resistance, investment costs, and others. Several factors are similar to [16] which shows that weak government efforts, poor knowledge of the benefits of BIM, and resistance to change are the main inhibiting factors for BIM adoption. The low level of BIM implementation is not due to a single problem, but rather a number of problems that are joined together. Several barrier factors of BIM adoption summarized from previous studies are presented in Table 1. 
The $1^{\text {st }}$ International Conference on Business and Management of Technology (IConBMT)

August 3rd 2019, Institut Teknologi Sepuluh Nopember, Surabaya, Indonesia

\begin{tabular}{ccc}
\hline \hline 9 & Lack of information about the process of changing business and how to change the process & [12], [19] \\
10 & The cost of BIM training and the recruitment of BIM specialist staff & {$[12],[16]$} \\
11 & Lack of trust in the integrity of BIM (BIM technology is not yet mature) & {$[6],[12],[19]$} \\
12 & Lack of BIM expert experts & [13], [15], [16] \\
13 & Interoperability (ability to interact with other systems such as exchanging information data etc.) & [7], [19]-[21] \\
14 & There are no clear standards and guidelines & [11], [13], [16], [19] \\
15 & Inadequate technological infrastructure & {$[16],[18],[22]$} \\
16 & Current technology is sufficient & {$[16]$} \\
17 & Lack of senior management support & {$[12]$} \\
18 & Resistance to change & {$[12],[15],[16],[18]$} \\
19 & Lack of client or government demand & {$[6],[13],[15],[16],[19]$} \\
20 & The market is still very diversified with regard to the use of digital work techniques & [22] \\
\hline \hline
\end{tabular}

TABLE 2. DRIVER FACTORS OF BIM ADOPTION

\begin{tabular}{|c|c|c|}
\hline Kode & Criteria & Source \\
\hline Driver.1 & Perceived usefulness & [20], [23]-[25] \\
\hline Driver.2 & Perceived ease to use & [14], [20], [23]-[25] \\
\hline Driver.3 & Relative advantage & [23]-[27] \\
\hline Driver.4 & Compatibility & [19], [20], [23], [24] \\
\hline Driver.5 & Complexity & [23], [24] \\
\hline Driver.6 & Trialability & [4], [19], [23] \\
\hline Driver.7 & Observability & [23] \\
\hline Driver.8 & Technology Factors & [14], [19], [23]-[27] \\
\hline Driver.9 & Top Management Support & [4], [20], [23], [27], [28] \\
\hline Driver.10 & Communication Behavior & [23], [26] \\
\hline Driver.11 & Organizational Readiness & [4], [20], [23], [29], [30] \\
\hline Driver.12 & Social Motivation & [21], [23] \\
\hline Driver.13 & Organizational culture & [14], [23] \\
\hline Driver.14 & Willingness / intention & [23]-[25], [28] \\
\hline Driver.15 & Organizational structure and size & [14], [23] \\
\hline Driver.16 & Coercive pressures (coercion by other organizations, such as government mandates) & [19], [21], [23], [25] \\
\hline Driver.17 & Mimetic pressures (The drive to imitate the success of other organizations) & [19], [21], [23] \\
\hline Driver.18 & Normative pressures (demands for professionalism) & [14], [20], [23], [28] \\
\hline
\end{tabular}

\section{B. Driver Factors of BIM Adoption}

Because of the barrier factors of BIM adoption, BIM's total adoption will remain a problem unless these barriers are removed immediately. After the barriers are gone, a driving factors is needed so that BIM's adoption is quickly realized. This section will highlight previous research related to the drivers of BIM adoption. Understanding the drivers and process of BIM adoption is a very important part of adopters and policy makers at broad organizational and market levels [23]. [20] tested empirical factors that could potentially facilitate BIM adoption by architects through an extension of the technology acceptance model (TAM) theory. The results of the study show that the support of top management, subjective norms, compatibility, and computer efficacy is an important factor that influences the behavior intention of architects to adopt BIM, through mediating the original factors of TAM, namely perceived usefulness and perceived ease to use. [4] developed a model using framework on the technology organization environment (TOE) theory to study the factors that influence BIM adoption by architectural companies in India. The results of the study showed that the expertise, trialability, and support of top management had a strong positive influence on BIM adoption. [19] have conducted surveys and interviews with quality surveyor (QS) consultants. The study explores several factors driving BIM adoption including quality information in models, case studies, analysis of benefits and costs, client requests, easy to use, already used in various industries, can be integrated with existing software, training scenarios. [21] use institutional theory to examine how three types of isomorphic pressure (coercive, mimetic, and normative) influence BIM adoption on construction projects. The results showed that coercive and mimetic pressure 
significantly affected the level of BIM adoption at the project level. However, the normative pressure did not significantly influence BIM adoption. Client or owner support is the most important driving factor in BIM adoption. Various researchers have explored the drivers of BIM adoption through various theoretical approaches. A list of factors driving BIM adoption from previous studies is collected in Table 2 .

\section{METHOD}

The overall research methodology consists of attribute identification, preliminary survey, and analysis. Following the attributes identification, a preliminary survey was performed, involving eleven experts from professional. The number of experts involved in this study was considered sufficient according to [31], the number of experts used to measure the attributes relevancy are at least three to five experts. This is supported by [29] who also used twelve experts in his preliminary survey. The expert involved in this preliminary survey were those who have been at least 10 years' experience in this field.

The purpose of the preliminary survey was to verify the attributes that have been identified from the literature. Semantic scale utilized 1-5 scales was used to calculate the attributes relevancy based on experts' opinion. Scale 1 that represents the variable is very irrelevant and scale 5 that represents the variable is very relevant. The next step was determining the sample, drafting the questionnaire, conducting a pilot test and questionnaire distribution through the main survey. A pilot test was aimed at ensuring that the respondents really understand the question to minimize the bias [29].

After the overall data is obtained from the main survey through the questionnaire, the samples were examined and cleaned first before the analysis. When the data has ready for the analysis, validity and reliability tests were carried out. Validity test was intended to check the questionnaire accuracy. An instrument can be said valid if it measures what should be measured or can give results in accordance to what the researcher expected. Meanwhile, a reliability test is needed to ensure that the measurement instrument has consistency to assess the attributes repeatedly [32]. Reliability is usually measured using Cronbach Alpha coefficient and an instrument is said to be reliable if this coefficient is greater than 0.60 [30].

\section{RESULTS AND ANALYSIS}

This paper presented an initial result of the research to investigate barrier and driver factors of BIM adoption in Indonesia. It covers the preliminary survey result based on the experts' survey which is presented with regard to the attributes relevancy and their rankings.

\section{Attributes Relevancy}

Data analysis from the experts' opinion can be represented in the attributes mean and standard deviation (SD) as can be seen in Table 3 and Table 4. In this study, 3.00 (three) score was used as the cut-off to determine the attribute relevancy as this value is the middle score between 1 to 5 . It means that the attributes were considered relevant if their means are larger than three $(\geq 3)$ as the middle value. As the means of the overall attributes were greater than three, all attributes were considered relevant to be used for the main survey through the questionnaire distribution. Based on the results of this preliminary survey, there are several variables that are omitted because they are considered irrelevant by showing mean values smaller than 3 (three). There are 4 variables on the barrier factors of BIM adoption that are not relevant according to BIM experts in Indonesia, while all the driver factors of BIM adoption are considered relevant.

Here are some opinions from BIM experts in Indonesia during the preliminary survey, contract or legal issues (data ownership) are not significant as a barrier factor of BIM adoption in Indonesia because if you already use BIM, the data is already open because BIM is collaborative, that means no data is hidden and BIM is building a trust culture. Although indeed in Indonesia there are no clear rules about who has the model and metadata, and in the contract there are very few provisions and procedures regarding BIM implementation. Another expert said that BIM had no different context with other software.

Inadequate technological infrastructure is also considered insignificant as an inhibiting factor for BIM adoption in Indonesia because in Indonesia, especially in large cities the internet network is quite good, even fiber optic networks are spread out. Likewise, the reliability of electricity is also quite good, especially in Indonesia that the server device is backed up by the uninterruptible power supply (UPS) so there will be no downtime due to power outages.

Inter-operability (the ability to interact with other systems such as information data exchanges etc.) is also considered insignificant as a limiting factor for BIM's adoption in Indonesia because currently BIM has good level interoperability so that it can be integrated with project scheduling, cost budgeting, and facility management. Even now in Indonesia, BIM is very good for interoperability collaboration. Exchange can already be done through the cloud or server, and through BIM the data exchange is semi real time.

The lack of BIM suitability for all types of building projects is also considered insignificant as an inhibiting factor for BIM's adoption in Indonesia because currently all types of development are able to use BIM, both buildings, infrastructure, bridges, roads, power plants, dam, channels, and others. Many types of BIM software are suitable for the needs of the type of project. 
The $1^{\text {st }}$ International Conference on Business and Management of Technology (IConBMT)

August 3rd 2019, Institut Teknologi Sepuluh Nopember, Surabaya, Indonesia

\section{Attributes Rangking}

Data analysis from the experts' opinion can be represented in the attributes mean and standard deviation (SD) as can be seen in Table 3 and Table 4 . In addition to the attributes relevancy, it is also important to find the attributes ranking based on experts' opinion. Based on Table 3, three most relevance attributes of barrier factor can be obtained from the experts' survey. The highest attribute of barrier factor was "Lack of BIM expert" (mean 4.36). This attribute was considered the most relevant attribute as the experts. This is in line with previous studies that the lack of experts ranks first in inhibiting BIM adoption [13], [15]. The main reason for not adopting BIM on current projects relates to the lack of expertise within the project team and external organisations. This could be the reason why the benefits of 3D modelling and BIM have not been fully realised in construction in a similar way to that documented in other industries such as car manufacturing and machinery design. It is hoped that the opportunities this indicates for education providers and industry through continuing professional development events will be seized and that the full financial benefits of BIM will be realised [15]. The second attribute of barrier factor ranking was "Lack of understanding about BIM and its benefits" with 4.27 as the mean value and 0.90 as standard deviation. This is in line with various previous studies, the lack of awareness of the benefits of BIM seen from the perspective of cost and benefit analysis has been ranked second as the inhibiting factor for BIM adoption by quantity surveyor (QS) consultants in Australia[19]. Likewise, according to [17] that it requires sufficient understanding of BIM to be able to implement BIM, and this is one of the three main factors which are challenges in the implementation of BIM in the construction industry in the UK. Lack of understanding of the benefits of BIM is also ranked third in the inhibiting factor for BIM adoption in Iraq due to a lack of self-development of most of those working in the Iraqi construction sector.

According to comments from BIM experts in Indonesia during the preliminary survey in this study that BIM was still seen as only a 3D visualization and model. Though BIM is not just a visualization and 3D model, it is more an integrated system that includes all information related to construction projects and is placed in a single model. This obstacle certainly needs to be removed first so that BIM's adoption in Indonesia can be fully realized.

This solution is in line with previous research that a comprehensive view of the benefits of BIM needs to be elaborated to help individuals and organizations both project owners, consultants and contractors to understand the BIM concept, this will be the main driving factor for efficient BIM adoption[4]. "Resistance to change" was ranked as the third place of barrier factor with mean value 4.27 and 1.01 as standard deviation. This attribute is also considered relevant because there was hardly any knowledge and awareness of BIM, so there was a strong resistance by the company to change its tool[18]. Even in design companies, most designers hesitate to use BIM because of habitual resistance to change[12]. The strong resistance to change, especially the large ages, and the engineers stuck to the software just familiar to them. Based on Table 4, three most relevance attributes of driver factor can be obtained from the experts' survey. The highest attribute of driver factor was "Willingness/intention" (mean 4.82). In the context of adopting new technology, a positive attitude can increase an individual's interest in learning BIM technology and thus increase the chances of successful adoption. Attitudes influence interest in learning.

TABLE 3.

BARRIER FACTORS OF BIM ADOPTION PRELIMINARY RESULTS

\begin{tabular}{|c|c|c|c|c|}
\hline Kode & Variable & Rank & Mean & Standard Deviaton \\
\hline Barrier.12 & Lack of BIM expert experts & 1 & 4,36 & 0,81 \\
\hline Barrier.2 & Lack of understanding about BIM and its benefits & 2 & 4,27 & 0,90 \\
\hline Barrier.18 & Resistance to change & 3 & 4,27 & 1,01 \\
\hline Barrier.10 & The cost of BIM training and the recruitment of BIM specialist staff & 4 & 4,09 & 1,22 \\
\hline Barrier.17 & Lack of senior management support & 5 & 4,09 & 1,22 \\
\hline Barrier.7 & Expensive costs for BIM implementation & 6 & 4,09 & 1,38 \\
\hline Barrier.8 & Doubt of return on investment (RoI) & 7 & 4,00 & 1,10 \\
\hline Barrier.3 & Lack of development of skills (BIM) & 8 & 4,00 & 1,18 \\
\hline Barrier.1 & Lack of BIM education and training & 9 & 4,00 & 1,41 \\
\hline Barrier.20 & The market is still very diversified with regard to the use of digital work techniques & 10 & 3,91 & 1,22 \\
\hline Barrier.6 & Lack of effective collaborative work processes between project participants & 11 & 3,82 & 1,25 \\
\hline Barrier.16 & Current technology is sufficient & 12 & 3,64 & 0,81 \\
\hline Barrier.19 & Lack of client or government demand & 13 & 3,55 & 1,57 \\
\hline Barrier.9 & Lack of information about the process of changing business and how to change the process & 14 & 3,45 & 1,29 \\
\hline Barrier.11 & Lack of trust in the integrity of BIM (BIM technology is not yet mature) & 15 & 3,18 & 1,08 \\
\hline
\end{tabular}


The $1^{\text {st }}$ International Conference on Business and Management of Technology (IConBMT)

August 3rd 2019, Institut Teknologi Sepuluh Nopember, Surabaya, Indonesia

\begin{tabular}{lllll}
\hline \hline Barrier.14 & There are no clear standards and guidelines & 16 & 3,09 & 1,30 \\
Barrier.4 & Contract or legal issues (ownership of data) & 17 & 2,91 & 1,38 \\
Barrier.15 & Inadequate technological infrastructure & 18 & 2,64 & 0,92 \\
Barrier.13 & Interoperability (ability to interact with other systems such as exchanging information data etc.) & 19 & 2,55 & 1,51 \\
Barrier.5 & Lack of BIM compliance for all types of development projects & 20 & 1,91 & 1,04 \\
\hline \hline
\end{tabular}

\begin{tabular}{llccc}
\hline \multicolumn{2}{c}{ TABLE 4. DRIVER FACTORS OF BIM ADOPTION PRELIMINARY RESULTS } & & \\
\hline \multicolumn{1}{c}{ Kode } & \multicolumn{1}{c}{ Variable } & Rank & Mean & Standard Deviaton \\
\hline Driver.14 & Willingness / intention & 1 & 4,82 & 0,40 \\
Driver.8 & Technology Factors & 2 & 4,73 & 0,47 \\
Driver.13 & Organizational culture & 3 & 4,64 & 0,50 \\
Driver.1 & Perceived usefulness & 4 & 4,64 & 0,67 \\
Driver.9 & Top Management Support & 5 & 4,64 & 0,67 \\
Driver.6 & Trialability & 6 & 4,55 & 0,82 \\
Driver.10 & Communication Behavior & 7 & 4,45 & 0,93 \\
Driver.16 & Coercive pressures (coercion by other organizations, such as government mandates) & 8 & 4,45 & 0,93 \\
Driver.4 & Compatibility & 9 & 4,36 & 0,50 \\
Driver.17 & Mimetic pressures (The drive to imitate the success of other organizations) & 10 & 4,36 & 0,92 \\
Driver.18 & Normative pressures (demands for professionalism) & 11 & 4,27 & 0,79 \\
Driver.11 & Organizational Readiness & 12 & 4,27 & 0,90 \\
Driver.7 & Observability & 13 & 4,27 & 1,10 \\
Driver.3 & Relative advantage & 14 & 4,09 & 0,83 \\
Driver.12 & Social Motivation & 15 & 4,00 & 1,26 \\
Driver.5 & Complexity & 16 & 3,73 & 1,01 \\
Driver.2 & Perceived ease to use & 17 & 3,64 & 1,29 \\
Driver.15 & Organizational structure and size & 18 & 3,36 \\
\hline \hline & & & 1,43 \\
\hline
\end{tabular}

When people are not afraid of the complexity of a technology, this will increase the effectiveness of BIM adoption[18]. Intention includes business interest in BIM innovation[23]. According to comments from BIM experts in Indonesia during the preliminary survey in this study that actually only needed in a matter of months to be able to implement BIM if there was intention. The second attribute of driver factor ranking was "Technological factors" with 4.73 as the mean value. This is in line with various previous studies, [14] stated that the main factor driving the adoption of BIM in Australia was a technological factor. Technology variables are very strongly emphasized in the [26] study to facilitate practical implementation by identifying promising areas and driving factors to increase the effectiveness of BIM. According to [27] technological factors are the main factors among the drivers of BIM adoption, including BIM technology functionality and design validation. Quality information in the BIM model is the most frequently cited driving factor for BIM adoption according to the most discussed research in[19]. Lack of information is a common problem in traditional methods where volume is calculated from 2D or 3D Computer-aided design (CAD) images. Visualization of design effects, supporting characteristics and features, information sharing ability is a derivative of technological factors as a driver of BIM adoption[23].

"Organizational culture" was ranked as the third place of driver factor with mean value 4.27 and 1.01 as standard deviation. The organisational culture brings adoption determinants such as the willingness to restructure or reengineer processes, adaptability to market, the corporate management style, the learning and growth perspective, the openness of discussions, and the availability of support for individual and group during the transition[23]. New roles and relationships within the projects teams are emerging. Dedicated roles such as BIM manager will be inevitable for large scale projects, as already seems to be some real world scenarios. Team members need training and information to be able to contribute and participate in the changing work environment[14].

\section{CONCLUSION}

Based on the analysis results using mean value according to the experts' opinion, it was found that all 16 barrier indicators and 18 driver indicators identified from the literature were considered relevant to be used to measure barrier and driver factors of BIM adoption in Indonesia. The three most relevant barriers BIM adoption in Indonesia attributes were also determined according to the experts' 
The $1^{\text {st }}$ International Conference on Business and Management of Technology (IConBMT)

August 3rd 2019, Institut Teknologi Sepuluh Nopember, Surabaya, Indonesia

opinion, that are (1) Lack of BIM expert; (2) Lack of understanding about BIM and its benefits; (3) Resistance to change. The three most relevant drivers BIM adoption in Indonesia attributes were also determined according to the experts' opinion, that are (1) Willingness/intention; (2) Technological factors; (3) Organizational culture.

\section{ACKNOWLEDGE}

The authors appreciate the experts who were involved in the preliminary survey in this research at year 2019.

\section{REFERENCES}

[1] Ž. Turk, "Ten questions concerning building information modelling,” Build. Environ., vol. 107, pp. 274-284, Oct. 2016.

[2] P. E. D. Love, J. Matthews, I. Simpson, A. Hill, and O. A. Olatunji, "A benefits realization management building information modeling framework for asset owners," Autom. Constr., vol. 37, pp. 1-10, Jan. 2014.

[3] D. Bryde, M. Broquetas, and J. M. Volm, "The project benefits of Building Information Modelling (BIM),” Int. J. Proj. Manag., vol. 31, no. 7, pp. 971-980, Oct. 2013.

[4] R. Ahuja, M. Jain, A. Sawhney, and M. Arif, “Adoption of BIM by architectural firms in India: technology-organizationenvironment perspective,” Archit. Eng. Des. Manag., vol. 12, no. 4, pp. 311-330, Jul. 2016.

[5] NBS, "NBS International BIM Report,” UK, 2016.

[6] M. Reza Hosseini, E. A. Pärn, D. J. Edwards, E. Papadonikolaki, and M. Oraee, "Roadmap to mature BIM use in Australian SMEs: Competitive dynamics perspective,” J. Manag. Eng., vol. 34, no. 5, pp. 1-13, Sep. 2018.

[7] G. Gegana and T. H. Widjanarso, "BIM Course Development and Its Future Integration At University Of Indonesia and Institute Of Technology Bandung Indonesia.” 9th BIM Academic Symposium \& Job Task Analysis Review, Washington, USA, 2015.

[8] Y. Hanifah, "Awareness dan pemanfaatan BIM: Studi eksplorasi,” in ProsidingTemuIlmiah IPLBI 2016, 2016, pp. H094-H054.

[9] BIM PUPR and Institut BIM Indonesia, Panduan Adopsi BIM dalam Organisasi. Jakarta: Pusat Litbang Kebijakan dan Penerapan Teknologi, 2018.

[10] KEMENPUPR and PT. PP, "Implementasi BIM (Building Information Modelling)," 2017.

[11] A. S. Telaga, "A review of BIM (Building Information Modeling) implementation in Indonesia construction industry," IOP Conf. Ser. Mater. Sci. Eng., vol. 352, no. 1, p. 012030, May 2018.

[12] C. Sun, S. Jiang, M. J. Skibniewski, Q. Man, and L. Shen, “A literature review of the factors limiting the application of BIM in the construction industry,” Technol. Econ. Dev. Econ., vol. 23, no. 5, pp. 764-779, Nov. 2015.

[13] K. Ku and M. Taiebat, "BIM experiences and expectations: The constructors' perspective,” Int. J. Constr. Educ. Res., vol. 7, no. 3, pp. 175-197, Jul. 2011.

[14] N. Gu and K. London, "Understanding and facilitating BIM adoption in the AEC industry,” Autom. Constr., vol. 19, no. 8, pp. 988-999, Dec. 2010.
[15] R. Eadie, H. Odeyinka, M. Browne, C. McKeown, and M. Yohanis, "Electronic journal of information technology in construction.," J. Inf. Technol. Constr., vol. 18, pp. 338-352, 2013.

[16] W. A. Hatem and A. M. Abd, "Barriers of adoption Building Information Modeling (BIM) in construction projects of Iraq," Eng. J., vol. 22, no. 2, pp. 59-81, 2018.

[17] A. Elmualim and J. Gilder, "BIM: innovation in design management, influence and challenges of implementation," Archit. Eng. Des. Manag., vol. 10, no. 3-4, pp. 183-199, Jul. 2014.

[18] Y. Arayici, P. Coates, L. Koskela, M. Kagioglou, C. Usher, and K. O’Reilly, "Technology adoption in the BIM implementation for lean architectural practice,” Autom. Constr., vol. 20, no. 2, pp. 189-195, Mar. 2011.

[19] A. Aibinu and S. Venkatesh, "Status of BIM adoption and the BIM experience of cost consultants in Australia,” J. Prof. Issues Eng. Educ. Pract., vol. 140, no. 3, p. 04013021, Jul. 2014.

[20] H. Son, S. Lee, and C. Kim, "What drives the adoption of building information modeling in design organizations? An empirical investigation of the antecedents affecting architects' behavioral intentions,” Autom. Constr., vol. 49, pp. 92-99, Jan. 2015.

[21] D. Cao, H. Li, and G. Wang, "Impacts of isomorphic pressures on BIM adoption in construction projects," J. Constr. Eng. Manag., vol. 140, no. 12, p. 04014056, Dec. 2014.

[22] P. Anker Jensen and E. Ingi Jóhannesson, "Building information modelling in Denmark and Iceland,” Eng. Constr. Archit. Manag., vol. 20, no. 1, pp. 99-110, Jan. 2013.

[23] A. L. Ahmed and M. Kassem, "A unified BIM adoption taxonomy: Conceptual development, empirical validation and application,” Autom. Constr., vol. 96, pp. 103-127, Dec. 2018.

[24] H. Xu, J. Feng, and S. Li, "Users-orientated evaluation of building information model in the Chinese construction industry,” Autom. Constr., vol. 39, pp. 32-46, Apr. 2014.

[25] J. Rogers, H.-Y. Chong, and C. Preece, "Adoption of Building Information Modelling technology (BIM),” Eng. Constr. Archit. Manag., vol. 22, no. 4, pp. 424-445, Jul. 2015.

[26] Y. Jung and M. Joo, "Building information modelling (BIM) framework for practical implementation,” Autom. Constr., vol. 20, no. 2, pp. 126-133, Mar. 2011.

[27] M.-H. Tsai, M. Mom, and S.-H. Hsieh, "Developing critical success factors for the assessment of BIM technology adoption: part I. Methodology and survey,” J. Chinese Inst. Eng., vol. 37, no. 7, pp. 845-858, Oct. 2014.

[28] V. Singh and J. Holmström, "Needs and technology adoption: observation from BIM experience," Eng. Constr. Archit. Manag., vol. 22, no. 2, pp. 128-150, Mar. 2015.

[29] M. A. Rohman, H. Doloi, and C. A. Heywood, "Success criteria of toll road projects from a community societal perspective," Built Environ. Proj. Asset Manag., vol. 7, no. 1, pp. 32-44, Feb. 2017.

[30] I. Ghozali, Aplikasi Analisis Multivariate dengan Program SPSS. Semarang: Badan Penerbit Universitas Diponegoro, 2005.

[31] D. F. Polit and B. P. Hungler, Nursing Research : Principles and Methods, 6th ed. Philadelphia: Lippincott, 1999.

[32] D. Sugiyono, Metode Penelitian Bisnis. Bandung: Pusat Bahasa Depdiknas, 2008. 